Article

\title{
High School and College Choice Factors Associated with High-Achieving Low-Income Students' College Degree Completion
}

\author{
Adriana Ruiz Alvarado ${ }^{1, *}$, Theresa Stewart-Ambo ${ }^{2}$ and Sylvia Hurtado ${ }^{3}$ \\ 1 Department of Leadership and Higher Education, University of Redlands, Redlands, CA 92373, USA \\ 2 Department of Education Studies, University of California, San Diego, La Jolla, CA 92093, USA; \\ tambo@ucsd.edu \\ 3 School of Education and Information Studies, University of California, Los Angeles, CA 90095, USA; \\ sylvia.hurtado@gmail.com \\ * Correspondence: adriana_alvarado@redlands.edu
}

Received: 8 May 2020; Accepted: 28 May 2020; Published: 2 June 2020

\begin{abstract}
Gaps in college degree completion between low-, middle-, and high-income college students are typically attributed to differences in academic preparation and ability. However, high-achieving, low-income students are still less likely to graduate from college than their high-achieving, high-income counterparts. This study explores completion rates at the end of the Great Recession, using a community cultural wealth framework to examine additional pre-college factors and college attendance behaviors that contribute to the degree completion of high-achieving, low-income students. Longitudinal data using the Freshmen Survey and National Student Clearinghouse were collected from 2004 to 2010, comparing 9300 high-achieving students entering 455 colleges from low-, middle-, and high-income backgrounds. Hierarchical linear modeling (HGLM) was used to identify student and institutional factors that predict college completion during this era. Findings indicate that navigational capital and college attendance patterns (attending a summer session, selective college, and/or private institution) are key factors for high-achieving, low-income student completion. Cultural wealth anti-deficit measures could not explain the low-income Latinx lower likelihood of college completion nor gender differences across income groups. Implications of the results address concerns regarding the COVID-19 pandemic recession in terms of what institutions can do to support students.
\end{abstract}

Keywords: college completion; high-achieving low-income students; community cultural wealth; intersectionality

\section{Introduction}

In the United States (U.S.), educational equality is a social justice issue of the 21st century. This is especially true when considering the social and economic mobility of students from disadvantaged backgrounds, for whom education can be a great equalizer. Studies that report the positive relationship between degree attainment, lifetime earnings, and social mobility highlight the importance of higher education for those from lower-income backgrounds, and on understanding factors affecting their degree attainment [1-3]. The achievement gap between low- and high-income students is often attributed to the former's lack of academic preparation and ability; however, in reality a degree completion gap persists between low-income and high-income students in the country regardless of their academic ability at college entry [4].

In fact, the most privileged students finish college at rates much higher than their less advantaged counterparts. In 2016, the bachelor's degree attainment rate in the U.S. by age 24 for students from the top income quartile was $58 \%$, compared to only $11 \%$ for students from the lowest income quartile [2]. 
These rates are alarming, but even more so is the gap in achievement between low- and high-income students that persists when controlling for students' academic ability. In this case, high-achieving, low-income (HALI) high school graduates are still less likely to persist and complete college compared to their high-achieving, high-income peers, regardless of the selectivity of the colleges attended [4-6]. Less is known empirically, however, about obstacles facing HALI students when achievement barriers, such as high school academic preparation, are removed. Thus, the purpose of this study is to examine additional pre-college factors and anticipated college experiences that are associated with the degree completion of HALI students in the U.S. during a period that included the Great Recession of 2008. There were reports of staff and faculty furloughs, reduction of majors and course offerings, and fewer resources for low-income students during this era [7]. At many U.S. higher education institutions, these issues might be similar to the conditions expected under the COVID-19 related budget cuts in higher education in 2020-2021.

Prior research examining low-income and working-class students in the U.S. has explored issues of academic preparation, access, choice, enrollment, financial aid, academic and social engagement, and retention and degree attainment [8-13]. Likewise, literature on high-achieving students explores issues of academic undermatch, overmatch, and mismatch in terms of the alignment of students' qualifications and ultimate college choice, as well as their cognition, interpersonal skills, civic engagement, and self-awareness [14-16]. Literature on the intersection of high-achieving and low-income status, though, is more limited. Most research explores the experiences of this group at selective or elite colleges, examines the practices and policies that can help them apply and ultimately choose to attend such colleges, or is descriptive in examining college completion [17-24]. Hoxby and Avery [22], for example, reported that the high-achieving, high-income students who apply to non-selective colleges where a larger percentage of applicants are admitted tend to be exceptions who are interested in specialty schools, whereas more than half of HALI students are "income-typical" and do not even apply to any selective institutions where the admissions process is highly competitive. A different descriptive study of completion rates demonstrated that while HALI students' college completion rates were lower than high-achieving, high-income students at the most selective colleges, the gap significantly increased at less selective institutions [4].

These findings are important, as disparities often associated with income status are obscured when discussing the degree attainment of high-achieving students. Broadly speaking, more needs to be known about factors that impact the degree completion of HALI students. This study aims to add to the current literature on HALI students by applying an asset-based framework to show pre-college factors and college attendance choices that contribute to their degree completion with implications for access and student support.

\subsection{Review of the Literature}

To foreground our examination of pre-college and anticipated in-college experiences, this review of the literature first provides an overview on low-income college students, followed by an in-depth focus on HALI students. Thereafter, we focus on degree attainment for HALI students and note this study's contribution to the literature. Finally, the theoretical framework describes our asset-based approach to understanding the topic.

\subsubsection{Low-Income College Students}

Low-income students tend to be from underrepresented minority communities, be the first generation to attend college, be financially independent, and have dependent children [25]. These characteristics make it difficult to separate issues of race, class, and generation status when talking about income and academic achievement, all of which can affect college outcomes. At the same time, not all low-income students share these demographic characteristics, which makes it particularly important to consider the intersection of different social identities when examining their experiences and outcomes, as well as those of other marginalized populations [26,27]. Intersectionality is a lens 
that acknowledges each social identity is associated with a system of power and that these systems interlock in different ways to create unique challenges or opportunities, which are further informed by contexts, historical events, and periodization [28,29]. For example, low-income Latinx students may experience more targeted bias and severe hardships during a recession than students of other race/ethnicities and income groups.

Because of these challenges and limited opportunities, low-income students in general tend to have lower academic preparation and achievement than their higher-income peers when entering college $[10,24,30,31]$, which often leads to remediation or developmental education, academic disillusionment, dropping out, or stopping out [10,32,33]. Research addresses low levels of academic and social engagement in college among low-income students, including fewer interactions with faculty and less involvement in extracurricular activities [9,34,35].

Focusing on all these characteristics without putting them into context for further explanation contributes to deficit thinking about low-income students. It is important to note that a distinctive feature of low-income college students is the need to work because they receive less financial support from their parents than their wealthier peers, may be self-supporting, or are expected to provide financial support for their family while in college $[9,17,30,36,37]$. The need to work, often full-time, limits opportunities to participate in a host of academic and social activities and also negatively affects degree attainment $[35,38]$. This may have been particularly important during the Great Recession, which not only affected families but also affected course offerings and faculty availability and staff support [7].

\subsubsection{HALI College Students}

As noted in the previous section, educational research has historically associated low-income students with low academic achievement. It is worth noting, however, that there are roughly 3.4 million students in the U.S. that rank in the top quartile of academically high-achieving students while falling below the national median with regards to income [4]. Because of the number of HALI students in the U.S., there is a growing field of research examining their access, transition, experiences, and academic attainment [17,36,39-41]. Thus, HALI students represent a unique intersection of achievement and economic status for further study. From the research, we know that this student population is less likely to graduate from college than their higher-income peers, at 59\% versus 77\%, respectively [4]. While there are limited empirical studies that address issues of completion, the growing field of research on HALI students qualitatively addresses several aspects of their college experience.

Scholars examining the experiences of low-income, working-class, and underrepresented minority populations at highly selective or elite universities have found that parental income and financial aid significantly alter students' in-college experiences and involvement [16,17,30,42,43]. As is the case for low-income students in general, financial stress is a common distraction for HALI students. Studies that have explored social engagement of low-income students at selective colleges around this topic $[42,44]$, many of which were conducted at Ivy League or private institutions, report finances to be a "daily issue" for HALI students. Comparing experiences between Black and White students, Aries and Berman [17] looked at class issues related to student transition, financial concerns, social adjustment, working during college, and supporting self and family at a selective private east coast college. Both low-income Black and White students in this study noted being aware of both their own social class status as well as that of their higher-income or affluent peers when moving into their residence halls. Students who shared that social class were indicated by material possessions such as computers, televisions, furniture, and clothing, which several students indicated they lacked [17]. These sentiments are echoed in a similar study [44] wherein students are reminded of their differences with peers and their inability to engage in class activities (e.g., class trips, technology requirements) and social involvements (e.g., sororities and fraternities) because of costs and lack of learning tools (e.g., laptops and cell phones). 


\subsubsection{HALI Students and College Completion}

Research on the "undermatch" phenomenon among HALI students is beginning to reveal a connection with degree attainment. With regard to high-ability students, research shows that high-ability students from low-income backgrounds tend to apply and enroll in less selective colleges than high-income students [22]. Moreover, high-ability students from low-income backgrounds tend to enroll at less selective institutions, or not enroll in college at all, rather than attend schools consistent with their high levels of academic achievement $[14,15,22]$. This phenomenon has been termed "undermatch." Baum, Ma, and Payea [1] found that, among high school graduates eligible for somewhat selective colleges, $8 \%$ of lower-socioeconomic students did not enroll anywhere and another $42 \%$ undermatched. Among those from upper-socioeconomic families, $3 \%$ did not enroll in college and $26 \%$ undermatched. These numbers are concerning given the relationship between institutional selectivity and improving chances for HALI student persistence and completion $[4,14]$.

It should be noted, however, that HALI students continue to complete at rates lower than high-achieving, high-income students at most colleges. Only at the most selective institutions is the gap between low- and high-income students minuscule [4]. As the selectively widens from most-selective to non-selective colleges attended, so does the disparity in degree completion between student income groups. For example, Wyner et al. [4] report that college graduation rates for HALI students correspondingly decreased from $90 \%$ for students attending a most-selective college to $56 \%$ for students attending a non-selective one. Comparatively, their high-income counterparts continued to complete at high rates regardless of selectivity. The implications of this gap are troubling because having a college degree is tied to social and economic mobility [45] and indicates colleges with more resources offer better opportunity for mobility.

Although the field of research on HALI college students is growing, no studies have yet examined the link between pre-college attributes (including other identities intersecting with family income) expectations, enrollment behavior, and college completion for this population. Extending current literature, this study uses national longitudinal data to examine these relationships for HALI students as well as their middle- and high-income peers. Moreover, much of the literature contributes to lower expectations for this group and does not explain how students manage to succeed in spite of the challenges they face. This study importantly takes an asset-based approach to illuminate factors that are related to HALI college student success across institutions of various types and selectivity levels, which can help colleges and universities better support these students in their educational journey.

\subsubsection{Theoretical Framework}

From the perspective of theorists who study the social reproduction of inequality in education, low-socioeconomic groups were not intended for access or completion at elite institutions. Pierre Bourdieu was the first to identify the concept of cultural capital, which affirms that cultural knowledge, skills, and abilities are passed down or inherited by privileged groups in society [46,47]. He argues that capital can be accumulated from family or through formal schooling, privileging the socially and culturally advantaged. Much of the research on low-income students focuses on the capital they lack (e.g., knowledge, access to opportunity, cultural norms of an educated class), whereas the present study will instead employ an asset-lens framework based on community cultural wealth.

In an attempt to shift away from the deficit frameworks applied to underserved racial/ethnic communities, Yosso [47,48] provides a theoretical model of community cultural wealth, which encompasses the various forms of capital that are rich in communities of color and can be used in order to resist oppressive forces. Yosso has identified six forms of interconnected capital that comprise community cultural wealth: (1) Resistant capital: Acknowledging when students challenge inequity and/or subordination, (2) Linguistic capital: Where communication through different languages and/or styles are seen as assets, (3) Navigational capital: One can learn to maneuver social institutions and barriers, (4) Social capital: Resources that are accessed through social networks, (5) Familial capital: Acknowledges the strength of cultural and/or family knowledge and histories, and (6) Aspirational 
capital: Acknowledging that aspirations and/or hope are motivating factors despite challenges. Current literature on HALI students does not address or identify aspects of students' lives that assist them in navigating postsecondary institutions and social mobility. Recent studies on Latinx and Asian American Pacific Islander college students reflect a precedence for applying community cultural wealth measures in quantitative research [49-51]. Similarly, we contend that this framework is appropriate in understanding patterns related to HALI students' degree completion from an asset-based approach. Aspects of the six forms of community cultural wealth were captured in this study as a way to identify strengths that HALI students bring with them to college.

\section{Methods}

\subsection{Data and Sample}

The longitudinal analysis for this study uniquely draws from two sources: (1) the 2004 administration of the Cooperative Institutional Research Program Freshman Survey (TFS), and (2) matched term-to-term enrollment data from fall 2004 to spring 2010 from the National Student Clearinghouse (NSC). The 2004 administration of the TFS was a year with the largest number of participating institutions and also with the most institutions that met norms criteria, signifying strong representation of both institutions and full entering cohorts that could be tracked longitudinally with NSC data [52]. The merging of these sources allowed for the examination of degree completion for 9300 high-achieving students who began college in 2004 at 455 different four-year institutions across the country during a six-year period that included the 2008 Great Recession. The 455 institutions included campuses that spanned the selectivity continuum and also varied in size and control (e.g., private or public). The sample of students included the 3100 HALI students that were participants in the dataset and are of primary interest in this study, and random samples of equal-sized middle- and high-income groups with similar academic qualifications that were drawn for comparison purposes. This random sample was drawn to allow for a comparison of models across groups that would be unaffected by sample size. Guided by previous research on HALI students, high-achieving students are defined as those who scored at least a 1300 math plus verbal composite score on the SAT and low-income status is defined as being in the lowest parental income quartile $(\$ 30,000$ or less) [4,23]. It is important to note that social class is a complex concept to operationalize, and family income only captures one component of it. Roughly half of the low-income sample (52.2\%) was female and one-fifth (20.6\%) was the first generation in their family to attend college. In terms of race and ethnicity, the sample was $62.9 \%$ White, $24.5 \%$ Asian American, $6.9 \%$ two or more race/ethnicities, 3.4\% Latinx, and $2.3 \%$ Black. American Indian students composed only five students in the HALI sample, and were therefore excluded from analysis. The sample of middle-income and high-income students are described in Appendix A, Table A1.

The large number of Asian American students, particularly in the HALI sample, is due to the operationalization of high-achieving using SAT scores. In general, there are relatively large numbers of White and Asian American students among the low-income population, which prevents class-based affirmative action practices from effectively targeting the most underrepresented groups for college access [53]. Research has shown that "the correlation between race and family income, while strong, is not strong enough to permit the latter to function as a useful proxy for race in the pursuit of diversity" in college admissions [54] (p. 32). The sample in this study reaffirms this is the case when standardized measures of ability such as strict cut-off SAT scores are applied.

\subsection{Measures}

\subsubsection{Dependent Variable}

The dependent variable, six-year degree completion, is a dichotomous measure derived from NSC data indicating whether a student graduated with a bachelor's degree within six years of starting 
college. Rather than reflecting whether students remained at the same institution where they began, the measure captures completion at any four-year institution in the higher education system because roughly one-third of students who begin in the four-year nonprofit sector after high school transfer to a different institution at some point during their trajectory [55]. Moreover, many students took courses at other colleges to complete or change majors during the recession [7]. The study, therefore, takes into account the student enrollment mobility that was required to complete degrees.

\subsubsection{Independent Variables}

The independent student-level variables that are based on previous literature, the theoretical framework, and the current financial crisis facing higher education include: Measures of students' social identity (demographics), the six forms of community cultural wealth, family and financial obligations, anticipated college experiences, college enrollment behavior, and institutional characteristics. Student social identity measures include sex, race, and generation status, which importantly acknowledge intersecting systems of power that influence the pre-college and college experience [27,28]. In estimating three separate analytical models, this study examines the intersection of these identities with family income in shaping students' college experiences and success.

Fourteen variables are included in the model to represent aspects of the six forms of community cultural wealth [47]. These include degree aspirations, whether students are native English speakers, and the role of parents in choosing to attend college as measures of aspirational, linguistic, and familial capital. Social capital is operationalized through two measures representing relationships in high school with teachers and other students.

Six measures including time management, number of colleges applied to, and various enrollments during high school and college that may demonstrate skill in maneuvering through higher education represent aspects of navigational capital. Specifically, the latter set of enrollment behavior includes the only measures in the study that capture students' actual college experiences rather than the ones they anticipate. Derived from NSC data, these include whether students enrolled in summer courses at their home institution, enrolled in summer courses at a different institution than the one where they began, or enrolled concurrently at two institutions during the traditional academic year. In addition to capturing aspects of navigational capital, these enrollment variables also capture college choice related to attendance, as students attempted to complete their degrees during or at the conclusion of the Great Recession when many courses had impacted enrollment or were not offered [7], as will likely become the case in the COVID-19 recession era.

The final form of cultural wealth has three measures in the analytic model, capturing a set of actions and goals that are meant to challenge the status quo. Among these is a construct that was previously validated by the Higher Education Research Institute [HERI] using item response theory [56]. Social agency is a six-item measure of the extent to which students place value on social and political involvement as a personal goal, and represents aspects of resistant capital [47]. Cuellar [49,50] found utility in several of these same measures to understand aspirational, familial, and resistant forms of cultural wealth in relation to Latinx students' college choice process. We extend the use of these cultural wealth measures by analyzing their relationships with college completion.

While Yosso [47] does not include economic capital and expands cultural capital in the community cultural wealth framework, as these traditionally value middle- and high-income culture, we also capture other forms of capital that Bourdieu [46] distinguishes. For example, economic capital and cultural capital are measured by financial obligations, home responsibilities, and first generation to attend college status. Research has found that family and financial obligations complicate the academic progress of low-income college students [9,21,38,39], and this study extends that work by quantitatively examining how such factors specifically influence degree completion for high-achieving students. The model captures the number of hours students spent per week in high school working for pay and taking care of household/childcare duties as proxies for potential responsibilities during college. Coupled with those measures is the distance of the college to the student's home, which can 
further influence the extent of financial and familial obligations. Concern about ability to pay for college and the amount of loans students expected to take out in their first year are also included in the analytic model. The final two student-level variables represent anticipated college experiences regarding employment and involvement in college life, which is also a five-item construct [56].

At the institutional level, the study includes measures for institutional selectivity and control to reflect the campuses where students entered in their first year of college. These are important as the link between selectivity and completion has been found to exist, not just for college students broadly, but for HALI students in particular [4]. Further, low-income students are more likely to undermatch by enrolling at less selective institutions regardless of high school achievement level $[14,15,22,57]$. We wanted to understand the extent to which HALI students are affected by the type of college they select as first year students, given the tendency to undermatch. Appendix A Table A1 presents descriptive statistics and coding schemes across the three samples for all of the independent variables in the final model. It also indicates measures where the middle- and high-income samples are significantly different from HALI students.

\subsection{Analysis}

Using the full sample of high-achieving students across the three income groups, descriptive statistics were first examined for outliers, multicollinearity, and missing cases. Because all but one variable had less than $5 \%$ missing values, the expectation maximization (EM) algorithm was used to impute values for missing cases on all measures except the dependent variable and demographic characteristics. EM uses maximum likelihood techniques to provide a more robust method than other missing value techniques such as listwise deletion or mean replacement [58]. The measure capturing the amount of loans students expected to take out during their first year of college had more than $10 \%$ missing values and, therefore, the results pertaining to this measure should be interpreted with caution.

Because the students in the database are nested within institutions and are not randomly assigned to colleges, multi-level modeling techniques were employed as research has demonstrated that single-level modeling of multi-level data may result in underestimated standard errors and lead to Type I statistical error [59]. Specifically, hierarchical generalized linear modeling (HGLM) analysis was used because it allows for an accurate estimation of both student and institutional-level characteristics on students' likelihood of degree completion, the dichotomous outcome. The same analytical model was used for all three high-achieving income groups.

\subsection{Limitations}

Several limitations are present in this study. First, with the exception of the enrollment measures from the NSC, all other independent variables reflect students' high school and anticipated college experiences reported on the first-year survey. As such, the findings do not tell the full story of why HALI students complete at lower levels than their higher-income counterparts. Nonetheless, the present analysis provides important insight into differences between the groups on several key factors. Secondly, it must be acknowledged that the measures representing community cultural wealth capture elements of all six forms but are certainly not exhaustive of each; future research may continue to develop and test CCW constructs. Lastly, our intention to include American Indians, because they are often relegated to an asterisk in quantitative research [60], was overcome by a very small sample size that was not sufficiently large enough for any meaningful interpretation of results. Future qualitative research may best capture their experiences that support degree completion.

\section{Results}

Descriptive results demonstrate that among all high achievers, $88.7 \%$ graduate college within six years. However, it is clear that, regardless of entering ability, high-income students do better as $91.3 \%$ of them complete their degrees in that time frame, compared to $88 \%$ of middle-income and $83.1 \%$ of 
low-income students. This is why understanding the factors that influence degree attainment for the low-income group of high achievers is critical as it can help to close the completion gap.

Table 1 shows the results of the HGLM analysis, predicting six-year completion for the three samples of high achievers-those from low-, middle-, and high-income backgrounds. In terms of background characteristics, females are more likely to complete college than high-achieving males across all three income groups (LI: $\mathrm{b}=0.355, p<0.01$; MI: $\mathrm{b}=0.055, p<0.001, \mathrm{HI}: \mathrm{b}=0.041, p<0.001$ ). Compared to low-income White students, low-income Latinx students have a lower probability of completion $(b=-0.648, p<0.05)$, but the difference is not significant among the other two income groups, indicating that the intersection of race and income is important to consider when examining degree attainment outcomes. Similarly, high-achieving Asian students from middle-income backgrounds are more likely to graduate in six years than their White peers $(b=0.033, p<0.05)$. Interestingly, no significant differences were found across racial groups among high-achieving, high-income students. Another interesting finding is that high-achieving multiracial students across all income groups do not differ in degree completion once all other factors are controlled.

Several measures capturing elements of students' community cultural wealth emerged as significant. Demonstrating the positive role of aspirational capital, low-income students who placed greater importance on going to college because their family wanted them to attend were more likely to graduate than low-income students who reported lower family aspirations $(b=0.158, p<0.05)$. Having high aspirations for their children's future is a form of cultural wealth that creates resilience and a culture of possibility $[47,61]$. This motivating factor was not a significant predictor among the other two higher income groups.

Two results highlighting the importance of navigational capital during high school for low-income students' success pertain to time-management skills and college application behavior. HALI students who rated themselves higher on time-management $(b=0.307, p<0.001)$ and those who applied to a greater number of colleges $(b=0.058, p<0.05)$ were more likely to earn a degree than those who reported lower values on those items. Though these measures do not explicitly acknowledge structures of inequality, they can easily be placed within such context. Because low-income students attend more poorly resourced high schools and typically have to balance more responsibilities [62,63], these factors demonstrate skill at maneuvering through the educational system. Time management proved be an important predictor across all three income groups and had a stronger effect among low-income students. The number of colleges students applied to was significant among low-income and middle-income students, presumably because they were able to receive better aid packages as a result, whereas the same measure was not significant in the high-income sample.

Navigational capital also plays a strong role during college, as HALI students who demonstrated skills in maneuvering through institutions by expediting their progress through enrollment in summer school at their home campuses were more likely to complete than students who did not take advantage of such opportunities $(b=0.625, p<0.001)$. This also applies to middle-income students $(b=0.059$, $p<0.001$ ), but high-income students were no more or less likely to finish when employing this strategy. On the other hand, summer school enrollment at a different institution was not significant for the low-income group but was a negative predictor for middle- $(b=-0.040, p<0.01)$ and high-income $(b=-0.043, p<0.01)$ students. Prior research found that such supplemental enrollment increased the odds of persistence in the higher education system relative to dropping out [64], whereas this study supports enrolling in the home institution rather than other institutions during summer. It is possible that students who sought summer enrollment elsewhere were less likely to complete in six years but continue to be enrolled in college. 
Table 1. Results of Hierarchical Generalized Linear Modeling (HGLM) Models Predicting Degree Completion for High-Achieving (HA) Low-Income, Middle-Income, and High-Income Students.

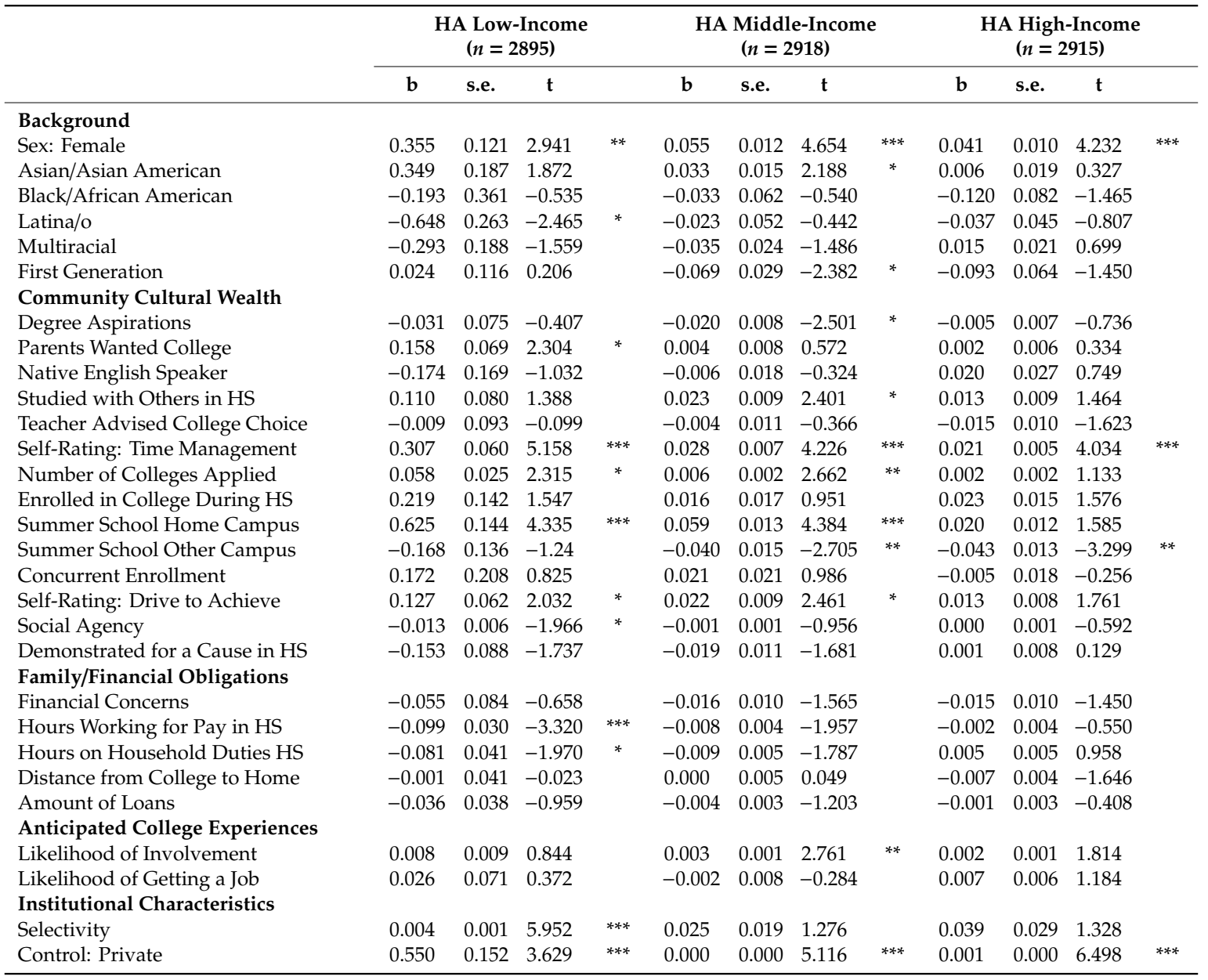

Note: ${ }^{*} p<0.05,{ }^{* *} p<0.01,{ }^{* * *} p<0.001$; Degree completion is defined as completing a bachelor's degree at any four-year institution in the higher education system. High-achieving is defined as having a 1300 or higher combined verbal and quantitative score on the SAT. Low-income is defined as having parental income below $\$ 30,000$; middle-income is parental income between $\$ 30,000$ and $\$ 149,999$; high-income is parental income of $\$ 150,000$ or higher. HS designates high school. Source: Cooperative Institutional Research Program, The Freshman Survey, 2004, and National Student Clearinghouse, Student Tracker, 2004-2010.

Given that low-income students are more likely to drop out throughout the entire educational pipeline [65], a drive to achieve represents a challenge to the status quo and a form of resistant capital. HALI students who indicated they had a higher drive to achieve compared to their peers were more likely to complete college than those who rated themselves lower on the measure $(b=0.127$, $p<0.05)$. As with application behavior, drive to achieve was not significant in the high-income sample. A surprising result pertaining to resistant capital is that low-income students' social agency is negatively associated with their degree completion $(b=-0.013, p<0.05)$, although HALI students who completed their degrees have significantly higher levels of social agency than those who had not completed (HALI completers $\mu$ : 47.6, HALI non-completers $\mu$ : 46.5, $\mathrm{t}(2980)=-2.3, p<0.05$ ).

HALI students who indicated that they spent more hours during high school working for pay $(b=-0.099, p<0.001)$ and tending to household and childcare duties $(b=-0.081, p<0.05)$ were less likely to complete within six years as these high school obligations likely continued in some capacity during college. It is possible that these obligations merely delay degree progress and these students still persist in the higher education system, but nonetheless, they deter six-year degree attainment. The two items associated with family responsibility, however, were not significant for the other two income groups, highlighting the critical role that financial security and multiple obligations 
can play in low-income student success. Interestingly, when controlling for these obligations, the likelihood of college involvement was only significant for the middle-income group $(b=0.003, p<0.01)$. Many types of college involvement activities are geared toward middle-class students, whose work and family obligations may be minimal, and their propensity to get involved increases their chances of completing college.

Lastly, both institutional characteristics had a significant and positive association with the outcome for HALI students. Confirming prior research [4], those at the most selective institutions were most likely to finish their degrees $(b=0.004, p<0.001)$, which is problematic given the higher rates of undermatching among this population and relatively small numbers of low-income students at the nation's most selective colleges [1,22]. Students across all three income groups were more likely to attain a degree in six years if they enrolled at a private institution compared with a public institution. This indicates that resource stratification is likely across institutions that provide further advantages for their high-achieving students, regardless of income.

\section{Discussion}

This longitudinal study presents a compelling examination of the six-year degree completion of high-achieving students from low-, middle-, and high-income backgrounds. The findings help us understand both some of the challenges and some of the assets that HALI students bring with them to college that may influence their degree attainment. Our results confirm that HALI students complete college at lower rates compared to high-achieving, middle- and high-income students. Disparities in educational attainment are an important social justice issue, and if colleges and universities do not find mechanisms to address students' obstacles or bolster student talent, they will only perpetuate social and economic inequalities through higher education. In this section, we discuss key findings and offer suggestions for institutions about how to better serve high-achieving students from low-income backgrounds.

Consistent with the literature, this study found that HALI students are more likely to complete if enrolled at a selective institution [4]. We found that even when controlling for a host of other pre-college experiences and goals outside of achievement, where students attend college still matters. Knowing this, proactive steps can be taken prior to and during college to help with the successful completion of low-income students. For example, high school counselors can encourage HALI students to apply to and enroll at institutions that more closely match their qualifications. Likewise, authority figures can share important knowledge with students regarding resources, campuses, and finances, which will ease transition and alleviate financial stressors that stall graduation. Hoxby and Avery [22] found that low-income students typically applied to schools that were consistent with their income (i.e., income typical) rather than consistent with their achievement (i.e., achievement typical). One approach to closing the gap and ensuring HALI students have a better chance at completing college is helping them attend a college that matches their ability and provides them with the support required to successfully complete (i.e., financial aid). Although this speaks to a larger educational issue related to appropriate college advising of disadvantaged students, it is important to recognize that students remain unaware about college financing and types of college options. Misconceptions abound regarding curricular options and college admissions processes that are detrimental to selection [24]. Pre-college preparation programs that recruit high-achieving students have begun to fill the information gap by encouraging students to apply to a larger number of institutions to be able to obtain the best financial aid packages and curricular programs, regardless of location [66]. This actually increases degree completion according to this study's findings, potentially reducing the number of hours students needed to work for pay during high school to save for college.

Selective colleges and universities also share responsibility for helping HALI students apply to and enroll at their campuses, where they are likely to be more successful. Some institutions have already taken efforts to do this by reducing the costs associated with applying, customizing messages encouraging low-income students to apply, partnering with high schools and community-based 
organizations to recruit, and paying for a campus visit prior to enrolling [20]. More institutions should follow suit in proactively recruiting talented students, and also in making efforts to decrease both perceived and real financial barriers. Additionally, several Ivy League institutions developed financial aid initiatives that offer generous financial aid packages to students from low-income backgrounds. Studies show that these programs have a range of success in increasing applications to and enrollment of low-income students [67]; therefore, elite institutions need to bolster efforts in promoting this financial opportunity.

This study reveals that students who worked during high school or had household and childcare duties were less likely to complete college in six years. Although we do not know for certain, we can infer that students who had such work or family obligations during high school likely continued to have them during college. Anticipation of such commitments coupled with high price tags at selective campuses are probably enough to deter enrollment. For that reason, it is of particular importance that institutions make clear the true net cost of college attendance after financial aid is taken into account $[19,20]$. The University of Michigan, for example, tested an intervention aimed at alleviating financial concerns by contacting families with encouragement to apply, along with a promise of four-years of free tuition if admitted [19]. Although most students ended up qualifying for more financial aid than the promised institutional tuition waiver, knowing the high price tag would not be the actual cost to their families resulted in HALI students being twice as likely to apply and enroll. It is important that colleges, along with other non-profit partners working with high school students, help families realize that financial aid can often make a competitive institution more affordable than many local less selective options. Lastly, regardless of institutional selectivity, all institutions should strive to help students who need to work find opportunities to do so on campus. This is especially important for institutions to consider during the current Covid-19 economic crisis, as many low-income families may be experiencing layoffs that further increase students' need to work during college or help at home.

Differing from much of the literature on the HALI population, this study used a community cultural wealth framework to examine key aspects of students' pre-college characteristics to predict completion. While students from disadvantaged backgrounds are often viewed through a deficit lens $[21,30,47,68]$, the community cultural wealth framework repositions students to be seen as having various forms of capital (i.e., familial, inspirational, navigational) that help them navigate oppressive institutions that were not designed for their success. This framework places the deficit framework on its head, emphasizing the knowledge, skills, strength, and resilience gained from students' communities.

Participation in summer school can be considered an aspect of navigational capital, which refers to "maneuvering through social institutions" [47] (p. 80) in order to complete college degree requirements. In this instance, we were interested in understanding how high-achieving students from different economic backgrounds strategically maneuver through the academic pipeline. The findings show that low- and middle-income students who enrolled in summer school at their home institutions were more likely to complete in six years than students who did not take advantage of this option. High-income students, on the other hand, were neither more nor less likely to finish due to having such enrollment. In contrast, both middle-income and high-income students who took summer courses at other institutions were less likely to finish in six years, presumably because they are trying to make up for courses they could not pass at their home institution. Institutions may want to consider providing aid for summer attendance or additional summer session opportunities for low-income students so that they may get ahead, or catch up, on academic coursework. Additionally, Summer Bridge programs, which not only help students transition to their home institution but also allow students a head start in their academic workload, may be important investments for colleges when looking for tried and true strategies that support navigational capital and completion for low-income students [69].

Yosso [47] refers to familial capital as the strength of cultural and/or family knowledge and histories. This tenet specifically pertains to kinship and a person's commitment to their community's well-being. Some previous literature on low-income students suggests that family may not be an 
asset in the college search and choice process, especially for first-generation students with parents who are unable to advise them when applying for and attending college [25]. Research on student experiences at elite colleges has found that some low-income students have to take on additional financial burdens to support themselves or their families during college $[17,30]$. While the literature tends to have conflicting views on the role of family on the college experience of HALI students, no studies had explicitly examined the role of family on their degree completion. The results of this study demonstrate that the aspirational capital derived from parents encouraging college attendance translated into success, whereas it does not serve the same function for middle- and high-income students. Using the community cultural wealth framework, we can infer that parents and family continue to play a valuable role in college completion, whether through encouraging them to complete or motivating them to aspire for a better life. More college preparation programs should actively seek to bring families in to assist with not only recruitment but also persistence initiatives to make use of aspirational capital. Moreover, educators in both the curricular and co-curricular sides of higher education institutions who are engaging with students virtually through stay-at-home orders across the country might find value in tapping into that aspirational capital in some way.

\section{Conclusions}

Educational attainment is an important issue, especially for individuals from disadvantaged backgrounds, as degree attainment can have broad implications for social and economic mobility. That being said, there continues to be much to learn about the degree attainment of high-achieving individuals from low-income backgrounds. The present study offers several new insights into the completion gap between high-achieving, low- and high-income students. First, the focus on one of the cohorts that was affected by the Great Recession may help to reemphasize the importance of financing college and institutional support under economic circumstances that are expected to be even more dire as a result of the Covid-19 pandemic. Future studies will help to reevaluate how important forms of support may change in different economic and social historical periods. Broadly speaking, we confirm that institutional selectivity matters in encouraging completion even when controlling for ability and other pre-college characteristics. The importance of attending the best colleges for which students qualify cannot be overestimated. Moreover, this study adds to the small but growing body of literature on this population by examining the link between pre-college characteristics and expected in-college experiences and college completion. Students continue to navigate colleges based on larger social factors as well as typical barriers encountered; maintaining strategic resilience is critical with the support of institutional agents. Finally, using a community cultural wealth framework, we offer an anti-deficit approach to examining factors impacting completion of HALI students. This study begins to also emphasize the intersectionality of income with race, class, and gender among students with similar high school academic assets, thereby identifying unique patterns of completion in the context of a specific historical time period [29]. More research is still needed to understand HALI students' experiences in different historical periods, and institutions should consider alternative strategies in addressing the unique needs of HALI students in order to increase social mobility as the best insurance in tough economic times. The current Covid-19 pandemic has exacerbated income inequalities [70] with little recourse for workers in some sectors who are losing jobs or facing health risks, while many of the best options are for those who have jobs that require a college education and offer the ability to work from home.

Author Contributions: Conceptualization, methodology, formal analysis, writing, editing, funding acquisition, project administration, A.R.A.; literature review, writing, editing, T.S.-A.; funding acquisition, project administration, writing, editing, S.H. All authors have read and agreed to the published version of the manuscript.

Funding: This research was funded by the Spencer Foundation, grant number 201300133; and the Jack Kent Cooke Foundation, grant number 20143272. 
Conflicts of Interest: The authors declare no conflict of interest. The funders had no role in the design of the study; in the collection, analyses, or interpretation of data; in the writing of the manuscript, or in the decision to publish the results.

\section{Appendix A}

Table A1. Description of High-Achieving (HA) Low-, Middle-, and High-income Samples.

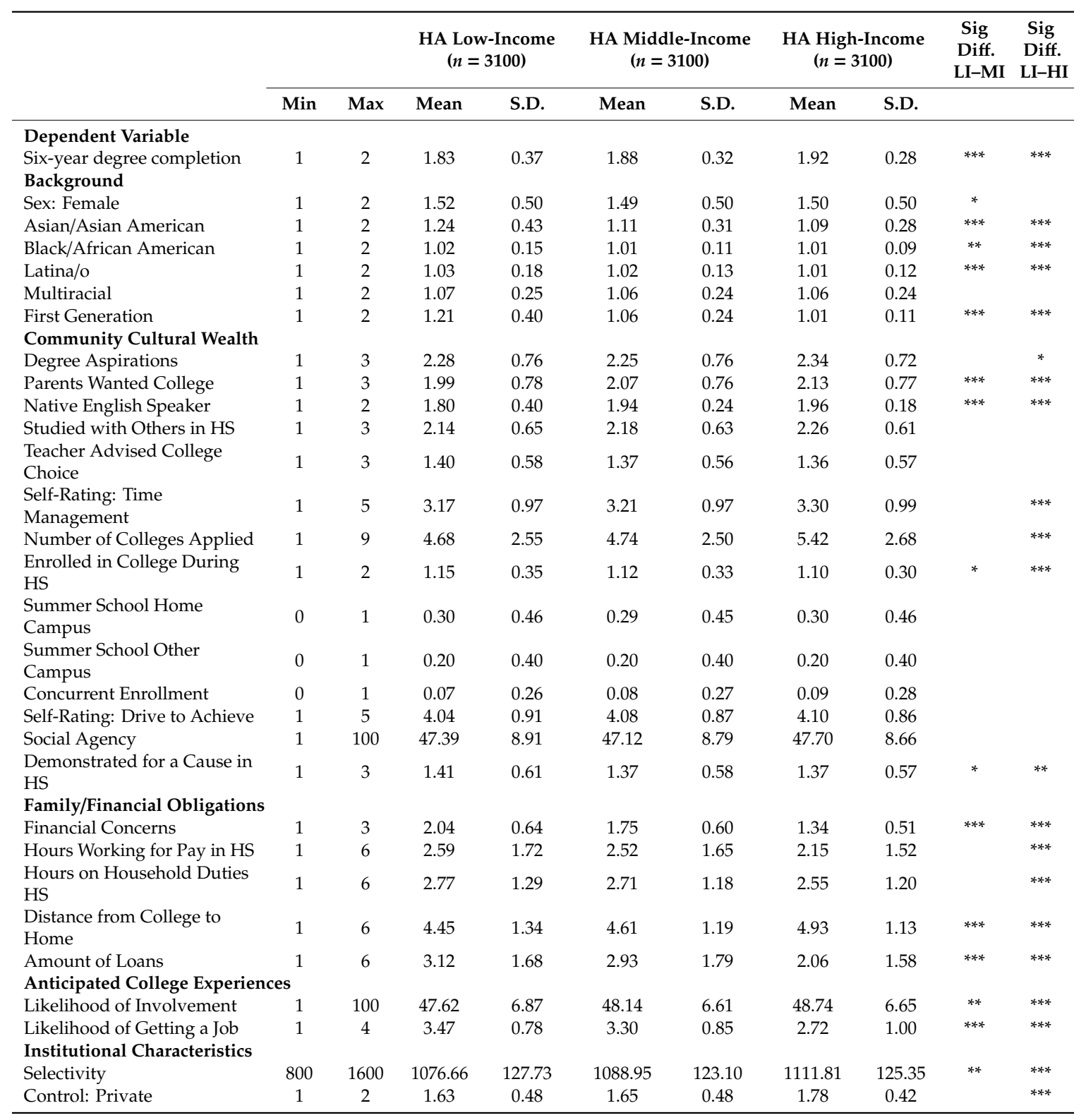

Note: ${ }^{* * *} p<0.001,{ }^{* *} p<0.01,{ }^{*} p<0.05$; Significant differences based on Dunnett T3 post-hoc test except for Sex, Studied with Other Students, Drive to Achieve, and Social Agency, which were based on Tukey's post-hoc test due to equal variances being assumed. Source: Cooperative Institutional Research Program, the Freshman Survey, 2004, and the National Student Clearinghouse, Student Tracker, 2004-2010. 


\section{References}

1. Baum, S.; Ma, J.; Payea, K. Education Pays 2013: The Benefits of Higher Education for Individuals and Society; The College Board: New York, NY, USA, 2013.

2. Cahalan, M.; Perna, L.W.; Yamashita, M.; Wright, J.; Santillan, S. Indicators of Higher Education Equity in the United States: 2018 Historical Trend Report; The Pell Institute for the Study of Opportunity in Higher Education, Council for Opportunity in Education (COE), and Alliance for Higher Education and Democracy of the University of Pennsylvania (PennAHEAD): Washington, DC, USA, 2018.

3. Cahalan, M.; Perna, L. Indicators of Higher Education Equity in the United States: 45 Year Trend Report; The Pell Institute for the Study of Opportunity in Higher Education: Washington, DC, USA, 2015.

4. Wyner, J.S.; Bridgeland, J.M.; Dilulio, J.J., Jr. Achievementrap: How America is Failing Millions of High-Achieving Students from Lower-Income Families; Jack Kent Cooke Foundation and Civic Enterprises: Washington, DC, USA, 2007.

5. DeAngelo, L.; Franke, R. Social Mobility and Reproduction for Whom? College Readiness and First-Year Retention. Am. Educ. Res. J. 2016, 53, 1588-1625. [CrossRef]

6. Franke, R. Towards the Education Nation: Revisiting the Impact of Financial Aid, College Experience, and Institutional Context on Baccalaureate Degree Attainment Using a Propensity Score Matching, Multilevel Modeling Approach. Ph.D. Thesis, University of California, Los Angeles, CA, USA, 2012.

7. Johnson-Ahorlu, R.N.; Alvarez, C.L.; Hurtado, S. Undermining the Master Plan: Divestment in Higher Education and Student Experiences. J. Coll. Admiss. 2013, 218, 22-35.

8. Astin, A.W.; Oseguera, L. The declining "equity" of American higher education. Rev. High. Educ. 2004, 27, 321-341. [CrossRef]

9. Engle, J.; Tinto, V. Moving Beyond Access: College Success for Low-Income, First-Generation Students; The Pell Institute for the Study of Opportunity in Higher Education: Washington, DC, USA, 2008.

10. Feliciano, C.; Ashtiani, M. How low-income origins affect postsecondary entry and degree completion. RISE- Int. J. Sociol. Educ. 2012, 1, 123-156.

11. King, J.E. The Decision To Go to College: Attitudes and Experiences Associated with College Attendance Among Low-Income Students; The College Board: Washington, DC, USA, 1996.

12. Muraskin, L.; Lee, J. Raising the Graduation Rates of Low-Income College Students; The Pell Institute for the Study of Opportunity in Higher Education: Washington, DC, USA, 2004.

13. Thayer, P.B. Retention of students from first generation and low income backgrounds. Oppor. Outlook 2000, 3 , 2-8.

14. Bastedo, M.N.; Jaquette, O. Running in place: Low-income students and the dynamics of higher education stratification. Educ. Eval. Policy Anal. 2011, 33, 318-339. [CrossRef]

15. Dillon, E.W.; Smith, J.A. The Determinants of Mismatch between Students and Colleges; No. w19286; National Bureau of Economic Research: Cambridge, MA, USA, 2013.

16. Kim, Y.K.; Rennick, L.A.; Franco, M.A. Latino College Students at Highly Selective Institutions: A Comparison of Their College Experiences and Outcomes to Other Racial/Ethnic Groups. J. Hisp. High. Educ. 2014, 13, 245-268. [CrossRef]

17. Aries, E.; Berman, R. Speaking of Race and Class: The Student Experience at an Elite College; Temple University Press: Philadelphia, PA, USA, 2013.

18. Cortes, K.E.; Lincove, J.A. Match or Mismatch? Automatic Admissions and College Preferences of Low- and High-Income Students. Educ. Eval. Policy Anal. 2019, 41, 98-123. [CrossRef]

19. Dynarski, S.; Libassi, C.J.; Michelmore, K.; Owen, S. Closing the Gap: The Effect of a Targeted, Tuition-Free Promise on College Choices of High-Achieving, Low-Income Students; No. w25349; National Bureau of Economic Research: Cambridge, MA, USA, 2018.

20. Glynn, J. Opening Doors: How Selective Colleges and Universities Are Expanding Access for High-Achieving, Low-Income Students; Jack Kent Cooke Foundation: Landsdowne, VA, USA, 2017.

21. Harper, S.R.; Griffin, K.A. Opportunity beyond affirmative action: How low-income and working-class Black male achievers access highly selective, high-cost colleges and universities. Harv. J. Afr. Am. Public Policy 2011, 17, 43-60.

22. Hoxby, C.M.; Avery, C. The Missing "One-Offs" The Hidden Supply of High-Achieving, Low Income Students; NBER Working Papers 18586; National Bureau of Economic Research: Cambridge, MA, USA, 2012. 
23. Hoxby, C.; Turner, S. Expanding College Opportunities for High-Achieving, Low Income Students; Stanford Institute for Economic Policy Research Discussion Paper: Palo Alto, CA, USA, 2013.

24. Hoxby, C.; Turner, S. What High-Achieving Low-Income Students Know About College. Am. Econ. Rev. 2015, 105, 514-517. [CrossRef]

25. Engle, J.; O'Brien, C. Demography Is Not Destiny: Increasing the Graduation Rates of Low-Income College Students at Large Public Universities; The Pell Institute for the Study of Opportunity of Higher Education: Washington, DC, USA, 2007.

26. Lundy-Wagner, V.C. Classifying Ethnicity/Race and Gender: An Intersectional Critique of Bachelor's Degree Completion Research. Interact. UCLA J. Educ. Inf. Stud. 2012, 8.

27. Museus, S.; Griffin, K. Mapping the margins in higher education: On the promise of intersectionality frameworks in research and discourse. New Dir. Inst. Res. 2011, 2011, 5-13. [CrossRef]

28. Crenshaw, K. Mapping the Margins: Intersectionality, Identity Politics, and Violence against Women of Color. Stanf. Law Rev. 1991, 43, 1241-1299. [CrossRef]

29. Nunez, A.-M. Employing Multilevel Intersectionality in Educational Research: Latino Identities, Contexts, and College Access. Educ. Res. 2014, 43, 85-92. [CrossRef]

30. Goodwin, L.L. Resilient Spirits: Disadvantaged Students Making It at an Elite University; Routledge: New York, NY, USA, 2016.

31. Kezar, A.J.; Walpole, M.; Perna, L.W. Engaging low-income students. In Student Engagement in Higher Education: Theoretical Perspectives and Practical Approaches for Diverse Populations; Routledge: New York, NY USA, 2014; p. 237.

32. Rosenbaum, P.R.; Rubin, D.B. The central role of the propensity score in observational studies for causal effects. Biometrika 1983, 70, 41-55. [CrossRef]

33. Terenzini, P.T.; Cabrera, A.F.; Bernal, E.M. Swimming against the Tide: The Poor in American Higher Education; The College Board: New York, NY, USA, 2001.

34. Jack, A.A. (No) Harm in Asking Class, Acquired Cultural Capital, and Academic Engagement at an Elite University. Sociol. Educ. 2016, 89, 1-19. [CrossRef]

35. Walpole, M. Socioeconomic status and college: How SES affects college experiences and outcomes. Rev. High. Educ. 2003, 27, 45-73. [CrossRef]

36. Bozick, R. Making It through the First Year of College: The Role of Students' Economic Resources, Employment, and Living Arrangements. Sociol. Educ. 2007, 80, 261. [CrossRef]

37. Kahlenberg, R.D. America's Untapped Resource: Low-Income Students in Higher Education; Century Foundation Press: New York, NY, USA, 2004.

38. DeAngelo, L.; Franke, R.; Hurtado, S.; Pryor, J.H.; Tran, S. Completing College: Assessing Graduation Rates at Four-Year Institutions; UCLA Higher Education Research Institute: Los Angeles, CA, USA, 2011.

39. Aries, E. Race and Class Matters at an Elite College; Temple University Press: Philadelphia, PA, USA, 2008.

40. Arzy, M.R.; Davies, T.G.; Harbour, C.P. Low Income Students: Their Lived University Campus Experiences Pursing Baccalaureate Degrees with Private Foundation Scholarship Assistance. Coll. Stud. J. 2006, 40, 750-766.

41. Boatman, A.; Long, B.T. Does Financial Aid Impact College Student Engagement? Evidence from the Gates Millennium Scholars Program. Res. High. Educ. 2016, 57, 653-681. [CrossRef]

42. Aries, E.; Seider, M. The interactive relationship between class identity and the college experience: The case of lower income students. Qual. Sociol. 2005, 28, 419-443. [CrossRef]

43. Reay, D.; Crozier, G.; Clayton, J. Strangers in Paradise? Working-class Students in Elite Universities. Sociology 2009, 43, 1103-1121. [CrossRef]

44. Hurtado, S.; Gasiewski, J.A.; Alvarez, C.L. The Climate for Diversity at Cornell University: Student Experiences; Cornell University: Ithaca, NY, USA, 2014.

45. Avery, C.; Turner, S. Student Loans: Do College Students Borrow Too Much-Or Not Enough? J. Econ. Perspect. 2012, 26, 165-192. [CrossRef]

46. Bourdieu, P. The forms of capital. In Handbook of Theory and Research for the Sociology of Education; Richardson, J., Ed.; Greenwood Publishing: New York, NY, USA, 1986; pp. 241-258.

47. Yosso, T.J. Whose culture has capital? A critical race theory discussion of community cultural wealth. Race Ethn. Educ. 2005, 8, 69-91. [CrossRef] 
48. Yosso, T.J. Critical Race Counterstories along the Chicana/Chicano Educational Pipeline; Routledge: Chicago, IL, USA, 2006.

49. Cuellar, M.G. Creating Hispanic-Serving Institutions (HSIs) and Emerging HSIs: Latina/o College Choice at 4-Year Institutions. Am. J. Educ. 2019, 125, 231-258. [CrossRef]

50. Cuellar, M.G. Latina/o students as agents of change: The influence of cultural assets and college experiences. Race Ethn. Educ. 2019, 1-21. [CrossRef]

51. Sablan, J.R. Can You Really Measure That? Combining Critical Race Theory and Quantitative Methods. Am. Educ. Res. J. 2019, 56, 178-203. [CrossRef]

52. Sax, L.J.; Hurtado, S.; Lindholm, J.; Astin, A.; Korn, W.; Mahoney, K. The American Freshman: National Norms for Fall 2004; UCLA Higher Education Research Institute: Los Angeles, CA, USA, 2004.

53. Kane, T.J. Misconceptions in the debate over affirmative action in college admissions. In Chilling Admissions: The Affirmative Action Crisis and the Search for Alternatives; Orfield, G., Miller, E., Eds.; Harvard Education Publishing Group: Cambridge, MA, USA, 1998.

54. Krueger, A.; Rothstein, J.; Turner, S. Race, Income, and College in 25 Years the Continuing Legacy of Segregation and Discrimination; Center for Economic Policy Studies Working Paper No. 108; Princeton University: Princeton, NJ, USA, 2005.

55. Hossler, D.; Shapiro, D.; Dundar, A.; Ziskin, M.; Chen, J.; Zerquera, D.; Torres, V. Transfer and Mobility: A National View of Pre-Degree Student Movement in Postsecondary Institutions; National Student Clearinghouse Research Center: Herndon, VA, USA, 2012.

56. Sharkness, J.; DeAngelo, L.; Pryor, J. CIRP Construct Technical Report; UCLA Higher Education Research Institute: Los Angeles, CA, USA, 2010.

57. Gladieux, L.E. Low-income students and the affordability of higher education. In America's Untapped Resource: Low-Income Students in Higher Education; Kahlenberg, R.D., Ed.; Century Foundation Press: New York, NY, USA, 2004; pp. 17-57.

58. McLachlan, G.J.; Krishnan, T. The EM Algorithm and Extensions; Wiley-Interscience: Hoboken, NJ, USA, 2008.

59. Raudenbush, S.W.; Bryk, A.S. Hierarchical Linear Models: Applications and Data Analysis Methods, 2nd ed.; Sage Publications: Thousand Oaks, CA, USA, 2002.

60. Shotton, H.J.; Lowe, S.C.; Waterman, S.J. Beyond the Asterisk: Understanding Native Students in Higher Education; Stylus Publishing: Sterling, VA, USA, 2013.

61. Gandara, P.C. Over the Lvy Walls the Educational Mobility of Low-Income Chicanos; State University of New York Press: Albany, NY, USA, 1995.

62. Balfanz, R.; Legters, N. Locating the Dropout Crisis: Which High Schools Produce the Nation's Dropouts? Where Are They Located? Who Attends Them; Report 70; John Hopkins Center for Research on the Education of Students Placed at Risk: Baltimore, MD, USA, 2004.

63. Rumberger, R.W.; Thomas, S.L. The Distribution of Dropout and Turnover Rates among Urban and Suburban High Schools. Sociol. Educ. 2000, 73, 39. [CrossRef]

64. Alvarado, A.R. Latina/o Pathways through College: Characteristics of Mobile Students and the Institutional Networks They Create. Ph.D. Thesis, University of California, Los Angeles, CA, USA, 2014. UMI 12710.

65. Chapman, C.; Laird, J.; KewalRamani, A. Trends in High School Dropout and Completion Rates in the United States, 1972-2008: Compendium Report; National Center for Education Statistics, Institute of Education Sciences, U.S. Department of Education: Washington, DC, USA, 2010.

66. Ruiz Alvarado, A.; Hurtado, S.; Stewart Ambo, T. The High-Achieving, Low-Income College Student Experience Study: Enrollment, Academic and Social Challenges, and Outcomes; UCLA Higher Education Research Institute: Los Angeles, CA, USA, 2017.

67. Avery, C.; Hoxby, C.; Jackson, C.; Burek, K.; Pope, G.; Raman, M. Cost Should be no Barrier: An. Evaluation of the First Year of Harvard's Financial Aid Initiative; No. w12029; National Bureau of Economic Research: Cambridge, MA, USA, 2006.

68. Harper, S.R. Leading the way: Inside the experiences of high-achieving African American male students. About Campus 2005, 10, 8-15. [CrossRef] 
69. Strayhorn, T. Bridging the pipeline: Increasing underrepresented students' preparation for college through a summer bridge program. Am. Behav. Sci. 2011, 55, 142-159. [CrossRef]

70. Reeves, R.; Rothwell, J. Class and Covid: How the Less Affluent Face Double Risk; Brookings Bull: Washington, DC, USA, 2020.

(c)

(C) 2020 by the authors. Licensee MDPI, Basel, Switzerland. This article is an open access article distributed under the terms and conditions of the Creative Commons Attribution (CC BY) license (http://creativecommons.org/licenses/by/4.0/). 